\title{
Optimal Planning of Charging and Power Delivering from/to the Network for Electric Vehicles Considering Types of Trip
}

\author{
Mahdi Samadi $^{\# 1}$, Ali Khanbabazade Afshar ${ }^{* 2}$ \\ ${ }^{\#}$ Department of Electrical Engineering, Hakim Sabzevari University, Sabzevar, Iran. \\ ${ }^{1}$ ma.samadi@hsu.ac.ir \\ * Department of Electrical Engineering, Neyshabur branch, Islamic Azad University, Neyshabur, Iran. \\ 2akf_ins@yahoo.com
}

\begin{abstract}
In this paper, a new model is proposed for optimal planning of daily charging and power delivering from/to the power system considering time schedule of trips for electric vehicles. In this model, trips are categorized in job, shopping, educational, and pleasure and possible times to charge/injection are considered based on type of trip and limitations of charging stations. In the optimal planning, it is assumed the hourly electricity price is known and also the rate of charging is fast. The load curve of system and also charging costs are analyzed which are important for system operator and car owners, respectively. Simulation results show by using the proposed planning for time scheduling of charge/injection, a smoother load curve is obtained and the costs of customer are decreased.
\end{abstract}

Keyword - Electric Vehicle, Charge Planning, Inter-Urban Trips, Charging Cost, Load Curve

\section{INTRODUCTION}

Recently, utilization of electric vehicle (EV) is introduced as an appropriate solution for reducing environmental pollutions [1]. Using a large number of electric vehicles in near future and increasing the consumed load due to electric cars charging, the power system maybe encountered with serious challenges. In fact, charging patterns of electric cars, especially in personal transportation, may affect the power system considerably, because of increase in peak load and feeder overload [2]. This implies the need for development of system facilities (e.g. generation system, distribution system) [3].

\section{A. Motivation}

In a system including considerable number of electric vehicles, the daily load curve of system is a function of charging pattern. Charging scheduling should not increase the peak load. On the other hand, suggested hours to charge/injection must be acceptable by the electric vehicle owners. Therefore, charging scheduling should consider the different working conditions of drivers as well as the load curve. Consequently, optimal planning of daily charging and also injection of extra energy of electric vehicles battery into the network considering trip time limits is very important.

\section{B. Contribution}

The main contribution of this paper is the proposing of a new optimal model for charging and power delivering planning from/to the network for electric vehicles. The proposed model minimizes the charging cost, in which, time scheduling of trips and station charging limitations are considered. In our model, four categories (including job, shopping, educational and pleasure) are considered based on the statistical information of transportation in Tehran city. The proposed planning for charging/injection, lead to customer satisfaction and improving the load curve of the system.

\section{Paper Organization}

The remainder of this paper is organized as follows. In Section 2, the literature is reviewed. Types of trips for electric vehicles are introduced in third section. Afterwards, the proposed framework for optimal charge/injection planning and the mathematical formulation are explained. Fourth section of this paper investigates the simulation results of the proposed model. In simulations, two scenarios (first scenario: only optimal charging, and second scenario: optimal charge/injection) are considered. Finally, conclusion is discussed in fifth section.

\section{LITERATURE REVIEW}

There are many works about planning for electric vehicle charging which some of them are mentioned. Researches about impacts of electric vehicle charging get backs to 1980 [5]. Negative effect of electric vehicle charging without planning on distribution network is discussed in [6]. Charging of electric vehicles without planning causes the overloading of distribution transformer and also the distribution network lines may be congested. Advantages of electric vehicles utilization, as an ancillary services in power system, are studied in [7]-[8]. 
In [9], the authors have proposed a model for optimal strategy for charging electric vehicles in an intelligent network with the objective of load variations minimization. The impact of electric vehicle charging on household load curve and its effectiveness on distribution transformer reliability is discussed in [10], and a solution for increasing the reliability is presented as well. Time reduction of long queue for vehicle charging is discussed in [11]. Technical limitation of vehicle charging from the network is ignored in this reference.

Electric vehicles charging optimization considering driving patterns is investigated in [12] beside different levels of vehicles penetration into distribution networks. Authors of this paper have considered slow charging rate. Slow charging will linearly and flatly change the load curve. Moreover, the more time for charging, because of slow charging, may be an undesirable issue for EV owners. The possibility of load leveling in a household micro grid is investigated in [13] by managing the charging pattern of electric vehicles. In this reference, the authors are used two vehicles to indicate the effects of different driving patterns and charging behavior on load curve. Besides, considering only technical requirements in objective function may be unacceptable for owners, which concern about their profits.

Reference [14] has tried to minimize the overall cost according to different charging patterns of electric vehicle. In [14], the impact of a direct load control program for management of electric vehicle charging process is analyzed. A novel method is proposed in [1] for load control of electric vehicle charging in response to time of use (TOU) pricing. Two centralized and decentralized optimization decision making are given in [15] for electric vehicles charging based on dynamic pricing model. The aim of both designs is minimization of charging costs by use of an optimal charging program. In [16], a dynamic optimization framework is presented for formulation of optimal charging problem.

A multi-objective planning method for electric vehicle charge/discharge in a smart grid is proposed in [17]. Results show that the proposed method for electric vehicle charge/discharge could reduce the operation. Reference [18], is proposed a new method, in which the trip time and consumption of charging energy is minimized during the path using a Genetic Algorithm. The impact of electric vehicles on the electricity market and distribution network is discussed in [19]. In most of studies, the technical limitations of charging station and the various trip types and driving pattern of electric vehicles are not considered simultaneously.

\section{III.PROPOSED METHOD}

\section{A. Types of Trips}

In order to propose a more realistic model for EV charging, some information about in urban transportation behavior of owners must be considered. According to studies of transportation and traffic organization of Tehran municipality, in urban trips objectives of citizens are divided into four groups: job, shopping, educational and pleasure trips [20]. Fig. 1 depicts the relative distribution of these groups in understudy samples.

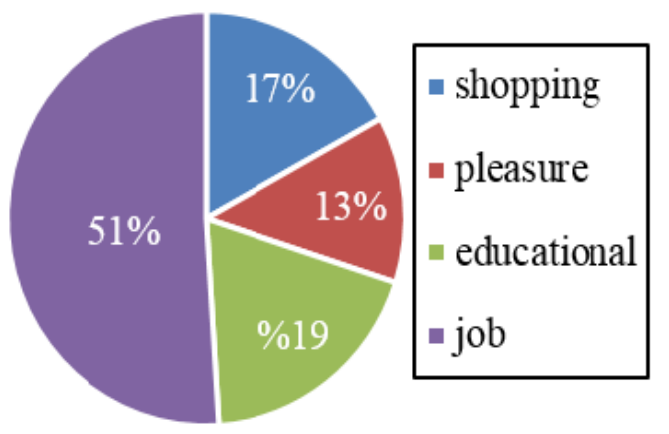

Fig.1: Relative distribution of trip objectives in Tehran [20]

The activity and stopping hours of each type, during the day, based on the objectives of the trip are represented in Table I [20]. Obviously, the electric vehicle could charge and deliver energy from/to the network only in stopping time.

TABLE II. The Activity and Stopping Hours of Each Trip Type

\begin{tabular}{|c|l|c|c|}
\hline Group & $\begin{array}{c}\text { Trip Type of } \\
\text { Personal Car }\end{array}$ & $\begin{array}{c}\text { Activity Time } \\
\text { Interval }\end{array}$ & $\begin{array}{c}\text { Stopping Time } \\
\text { Interval }\end{array}$ \\
\hline A & Job & $06: 00$ to $20: 00$ & $21: 00$ to $05: 00$ \\
\hline B & Shopping & $07: 00$ to $22: 00$ & 23:00 to 06:00 \\
\hline C & Educational & $06: 00$ to $19: 00$ & 20:00 to $05: 00$ \\
\hline D & Pleasure & $06: 00$ to $22: 00$ & 23:00 to $05: 00$ \\
\hline
\end{tabular}




\section{B. Problem Formulation}

In this section, the proposed model for electric vehicle charge/injection planning considering the schedule of vehicles trips is introduced. The electric vehicle is able to connect to the network for charging from grid to vehicle (G2V), or for injecting the remained power of its battery into the grid (V2G). In charge/injection planning owners maximize their benefit of charge selling and minimize the charging costs considering the trip plan of vehicles. Therefore, we proposed an objective function as (1):

$$
\operatorname{Max} \sum_{i=1}^{T} \sum_{j=1}^{N}\left|p_{i j}^{\prime} \pi_{i j}^{\prime} t_{i j}^{\prime}\right|-\sum_{i=1}^{T} \sum_{j=1}^{N} p_{i j} \pi_{i j} t_{i j}
$$

In (1), the first and second term relate to earned income of selling and charging cost respectively. The used indices are as follow:

i: hour of charging or injecting power to network (T: hours of planning period)

$\mathrm{j}$ : the number of electric vehicle (N: number of vehicles)

$p_{i j}$ : Rate of charging for vehicle $\mathrm{j}^{\text {th }}$ in hour $\mathrm{i}^{\text {th }}$

$\pi_{i j}$ : cost of electricity in hour $\mathrm{i}^{\text {th }}$ for charging vehicle $\mathrm{j}^{\text {th }}$

$t_{i j}$ : Binary variable for charging time of vehicle $\mathrm{j}^{\text {th }}$ in hour $\mathrm{i}^{\text {th }}\{0$ or 1 , which 1 is used for charging of vehicle in the station)

$p_{i j}^{\prime}$ : Rate of injection from vehicle $\mathrm{j}^{\text {th }}$ to the network in hour $\mathrm{i}^{\text {th }}$

$\pi_{i j}^{\prime}$ : Price of power injection from vehicle $\mathrm{j}^{\text {th }}$ to the network in hour $\mathrm{i}^{\text {th }}$

$t_{i j}^{\prime}$ : Integer variable for injection time of vehicle $\mathrm{j}^{\text {th }}$ in hour $\mathrm{i}^{\text {th }}\{0$ or -1 , which -1 is used for power delivering in to the network in the station)

In proposed model, the charging process in an hour is modeled by a binary variable ( 0 or 1$)$. As the injection of vehicle power to the network decreases consumed load in connection point to the network, the power injection is considered as an integer variable $(0$ or -1$)$. Constraints of optimization problem are presented in equations (2) to (8). The explanations of each constraint are given after the equations.

$$
\begin{array}{ll}
\sum_{i=1}^{24} p_{i j} t_{i j}=C_{\text {battery }} & \forall j=1,2, \ldots, N \\
\sum_{j=1}^{N} p_{i j} t_{i j} \leq P_{\text {station }}^{\prime} & \forall i=1,2, \ldots, 24 \\
\sum_{i=1}^{24}\left|p_{i j}^{\prime} t_{i j}^{\prime}\right|=C_{\text {Remain battery }} & \forall j=1,2, \ldots, N \\
\sum_{j=1}^{N}\left|p_{i j}^{\prime} t_{i j}^{\prime}\right| \leq P_{\text {station }}^{\prime} \quad \forall i=1,2, \ldots, 24 \\
\left\{\begin{array}{ll}
\sum_{i=1}^{5} t_{i j}+\sum_{i=21}^{24} t_{i j}=C_{r} & j \in\{A\} \\
\sum_{i=1}^{6} t_{i j}+\sum_{i=23}^{24} t_{i j}=C_{r} & j \in\{B\} \\
\sum_{i=1}^{5} t_{i j}+\sum_{i=20}^{24} t_{i j}=C_{r} & j \in\{C\} \\
\sum_{i=1}^{5} t_{i j}+\sum_{i=23}^{24} t_{i j}=C_{r} & j \in\{D\}
\end{array}\right\}
\end{array}
$$




$$
\begin{aligned}
& \left\{\begin{array}{l}
\sum_{i=1}^{5} t_{i j}^{\prime}+\sum_{i=21}^{24} t_{i j}^{\prime}=D_{r} \quad j \in\{A\} \\
\sum_{i=1}^{6} t_{i j}^{\prime}+\sum_{i=23}^{24} t_{i j}^{\prime}=D_{r} \quad j \in\{B\} \\
\sum_{i=1}^{5} t_{i j}^{\prime}+\sum_{i=20}^{24} t_{i j}^{\prime}=D_{r} \quad j \in\{C\} \\
\sum_{i=1}^{5} t_{i j}^{\prime}+\sum_{i=23}^{24} t_{i j}^{\prime}=D_{r} \quad j \in\{D\}
\end{array}\right\} \\
& t_{i j} \times t_{i j}^{\prime}=0 \quad \forall i=1,2, \ldots, 24 \quad, \forall j=1,2, \ldots, N
\end{aligned}
$$

Equation (2) guarantees the complete charging of vehicle battery from network, which $C_{\text {battery }}$ shows capacity of battery in terms of KWh. Equation (3) indicates the limitation of vehicles connection to the network for simultaneously power charging according to technical limitation and station capacity. Equation (4) represents the total deliverable energy to the network by a vehicle, which $\mathrm{C}_{\text {Remain battery }}$ shows the capacity of remained energy of battery after finishing the in-urban trip. Equation (5) is similar to (3) but this is for power delivering limitations. Equation (6) describes the time limitation of vehicles charging according to aim of trips (Table I). If vehicle $\mathrm{j}^{\text {th }}$, is stopped in hour $\mathrm{i}^{\text {th }}$, it could proceed to charge up. In this case, $\mathrm{t}_{\mathrm{ij}}$ value is equal to 1 and otherwise it would be equal to $0 . C_{r}$ is the required time for vehicle charging according to charging rate.

Equation (7) is similar to (6), but it shows the permissible hours for injection of power to the network in accordance with Table I. In fact, vehicle $\mathrm{j}^{\text {th }}$ could start to power injection if this vehicle, related to each of A, B, $C$ and D groups, stop completely in hour $i^{\text {th }}$. In this case, $t_{i j}$ value is equal to -1 , otherwise it would be $0 . D_{r}$ is the required time for vehicle discharge and its injection to the network according to charging rate and speed. Equation (8) declares that vehicle $\mathrm{j}^{\text {th }}$ could not perform charge and injection simultaneously. Vehicle owners proceed to plan charge/injection using information of electricity buying and selling price. However, time constrains corresponding to vehicle trip pattern and technical constraints of station are observed well in the proposed model.

C. Case Study

For examination of the proposed model, a system with following characteristics is studied. A 25 KVA transformer supplies the required energy for charging station of electric vehicles. Some loads including many household and commercial consumers are also connected to this transformer. It is supposed that each vehicle charging is done fast with the rate of $4 \mathrm{Kwh}$ per hour.

The charging capacity of station is considered $12 \mathrm{~kW}$ per hour, and the overall number of vehicles is assumed 26. According to relative distribution of vehicles, based on presented information in Fig. 1, the number of vehicles of "job", "shopping", "educational" and "pleasure" groups are considered 14, 4, 5 and 3 respectively. Battery capacity of each vehicle is $4 \mathrm{~kW}$. Regarding the fast rate of charging, $C_{R}$ and $D_{R}$ would be equal to one. Buying and selling price of electricity energy during the day is considered as multi-tariff rate. Table IV in appendix presents the prices in a day during the hot season of year. The planning is performed for a day $(T=24)$.

\section{IV.SIMULATION RESULTS}

At first, to indicate the importance of technical constraints subject, planning of vehicles charging is simulated without considering the limitation of station capacity. (In fact, constraint of station capacity and all the terms related to discharge modeling in optimization problem, introduced in section 3.2, are ignored.) Simulations are performed in two states: 100\% (full charge) and 75\% charge of battery. Fig. 2 shows the effects of electric vehicles charging with fast rate on electric load consumption curve, without considering the technical requirements of charging station. 


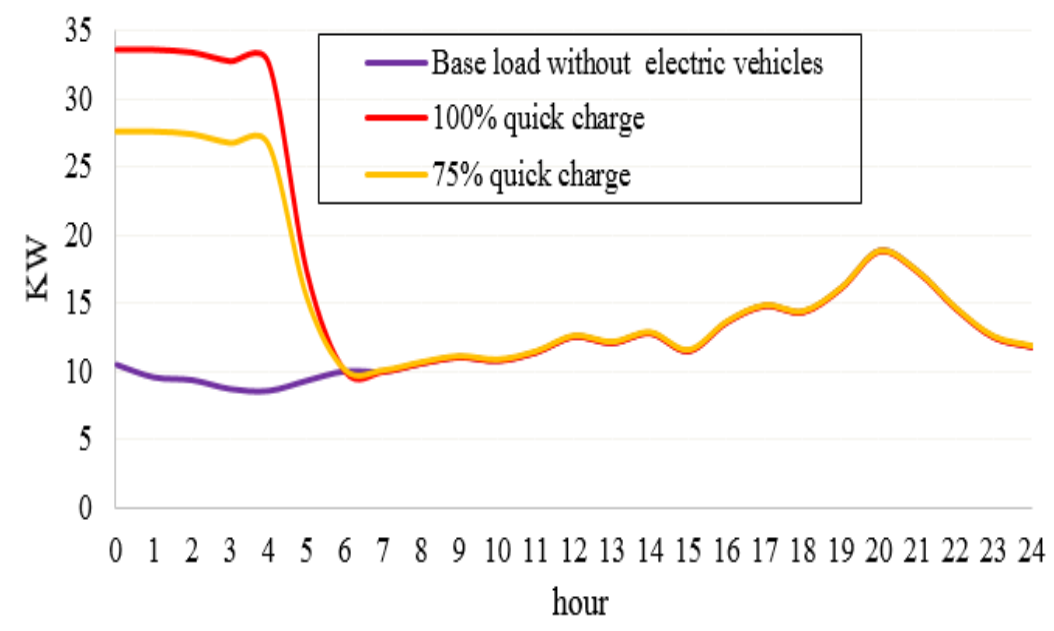

Fig. 2. The effects of electric vehicles charging on load

According to Fig. 2, adding the load arisen from electric vehicles charging could make a danger for distribution transformer. In this condition the owners proceed to charge the vehicle in a time that the electricity price is in the lowest level, without considering the capacity of charging station. Accordingly, such planning leads to create a new peak in early hours of a day. This issue is an undesired matter and could leading to out the distribution transformer.

In following sections, simulation results are presented in two scenarios by supposing the technical limitation of charging station. Optimal planning is simulated for two scenarios: the first: only charging program and the second: optimal charge/injection program.

\section{A. Scenario 1: Planning of Electric Vehicles Charging (with the Consideration of Required Constraints)}

In this scenario, vehicles owners proceed to charge their vehicle optimally by fast rate, while they are aware about the electricity price. (The vehicles don't have any contribution in selling and delivering the power to the network.) That is to say, injection modeling terms in optimization problem are not considered. Fig. 3 depicts the optimal charging planning obtained from implementation of proposed method.

This result relates to the supposed first case for remained charge (fully empty battery).

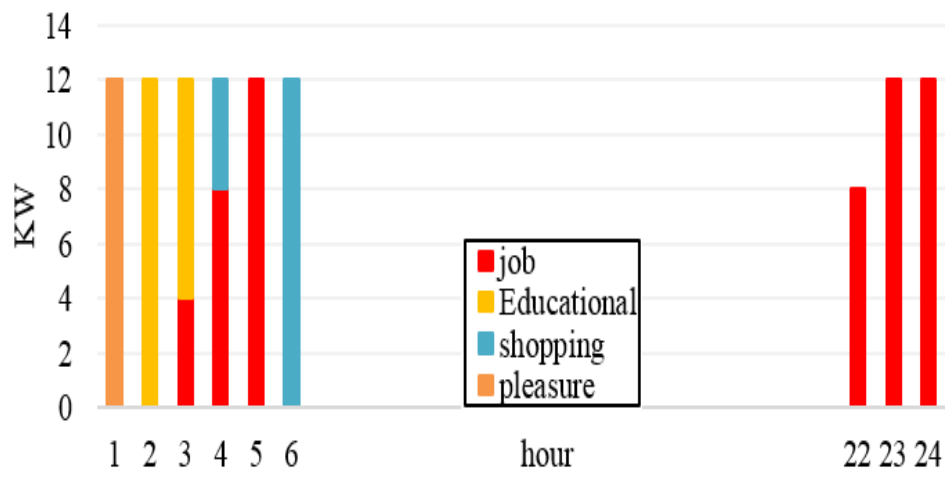

Fig. 3. Optimal planning of vehicles charging in first case (remained charge of battery is zero)

As shown in Fig. 3, all the vehicles of "pleasure" group (with the minimum number) are charged in duration of one hour, but the vehicles of "job" group (with the maximum number) proceed to charge between 3-5 o'clock and 22-24 o'clock. In all hours of charging, the maximum consumed power of charging station is equal to 12 $\mathrm{kW}$. The optimal charging planning corresponding to fifth case of remained charge (25\% percent of battery capacity) is presented in Fig. 4. 


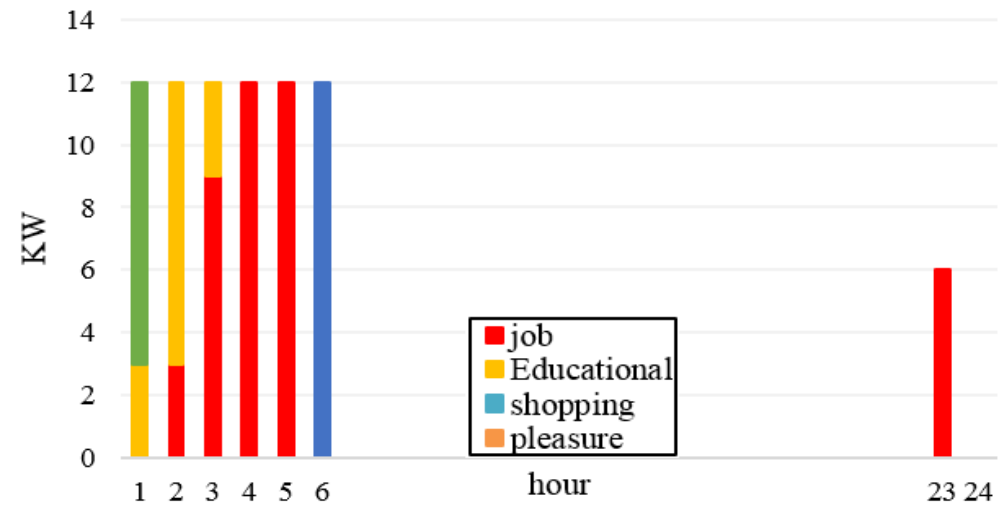

Fig. 4. Optimal planning of vehicles charging (when the remained charge of battery is equal to $25 \%$ of battery capacity)

With careful consideration of Fig. 4 and comparing it with Fig. 3, it is understood that the remained charge affects the charging planning of vehicles considerably. For instance, vehicles of "shopping" group succeed to charge themselves during 1 hour in this case. Moreover, according to figures 3 and 4, stopping limitation of each group of vehicles is observed in proposed planning. Similarly, planning for other supposed cases is performed separately for remained amount of charge. For investigation of charging planning effect from operator point of view, the total load curve (initial load curve plus charging station load) is drawn in Fig. 5 for five cases.

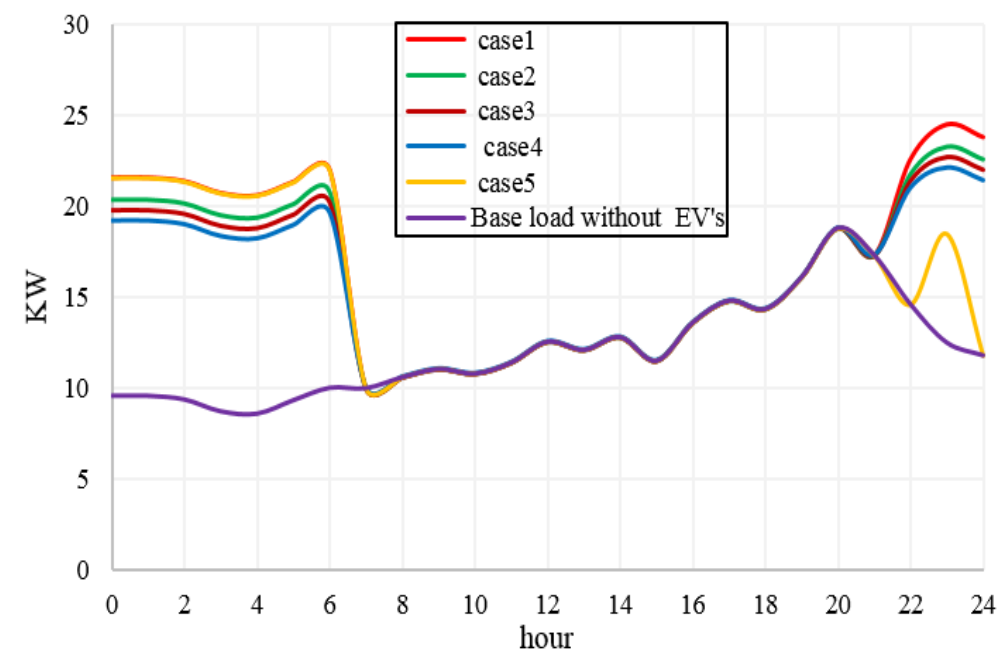

Fig. 5. The total load curve in first scenario (only the planning of vehicles charging)

As we can see in Fig. 5, peak load level is less than $25 \mathrm{~kW}$ (transformer capacity) in all cases. The maximum peak load relates to first case in which thevehicles require $100 \%$ charging. The peak load is equal to $24.5 \mathrm{~kW}$ in this case. Moreover, the valley of load curve in initial and final hours of day are filled in all cases. The trip program of vehicles (based on Table I) is observed thus the load curve is not changed charge in middle hours of the day. The load curve characteristics in presence of electric vehicles are gathered in Table II in summary.

TABLE IIIIV. The Impact of Optimal Charging Planning of Vehicles on the Load Curve

\begin{tabular}{|c|c|c|c|}
\hline Case & Peak Load & Average Load & Consumed Load \\
\hline 1 & $24.5 \mathrm{Kw}$ & $16.48 \mathrm{Kw}$ & $395.65 \mathrm{Kw}$ \\
\hline 2 & $23.3 \mathrm{Kw}$ & $16.05 \mathrm{Kw}$ & $385.25 \mathrm{Kw}$ \\
\hline 3 & $22.70 \mathrm{Kw}$ & $15.83 \mathrm{Kw}$ & $380.05 \mathrm{Kw}$ \\
\hline 4 & $22.10 \mathrm{Kw}$ & $15.61 \mathrm{Kw}$ & $374.85 \mathrm{Kw}$ \\
\hline 5 & $22.02 \mathrm{Kw}$ & $15.40 \mathrm{Kw}$ & $369.65 \mathrm{Kw}$ \\
\hline Without EV & $18.80 \mathrm{Kw}$ & $12.15 \mathrm{Kw}$ & $291.65 \mathrm{Kw}$ \\
\hline
\end{tabular}

As it can be seen in Table II, peak load hour in the network is changed from 20 o'clock to 23 o'clock by entering the electric vehicle (except than case 5). Considering that the vehicle requires the minimum amount of charge in case 5, hence the peak load time is shifted to low load hour of system (6 o'clock in the morning). Flexibility of consumed load of electric vehicle charging leads to optimal charging planning. As a result, peak load level doesn't exceed $24.5 \mathrm{~kW}$. 


\section{B. Scenario 2: Charge/Injection Planning of Electric Vehicles (with the Consideration of Required Constraints)}

In this section, proposed objective function (introduced in equation 1) and related constraints (equations 2 to 8) are simulated completely. In this scenario, owners could earn benefit from selling the remained energy to the network and decrease their costs. Therefore, for traveling or selling the electricity, they proceed to charge the vehicle fully in hours that the energy price is cheaper, and according to remained power in battery, they proceed to inject the energy to the network in hours that the electricity selling price is high. In Fig. 6, charge/injection planning of vehicles is drawn in case 1 (the remained charge is $10 \%$ ). Investigation of first case (battery without charge) is ignored in this scenario.

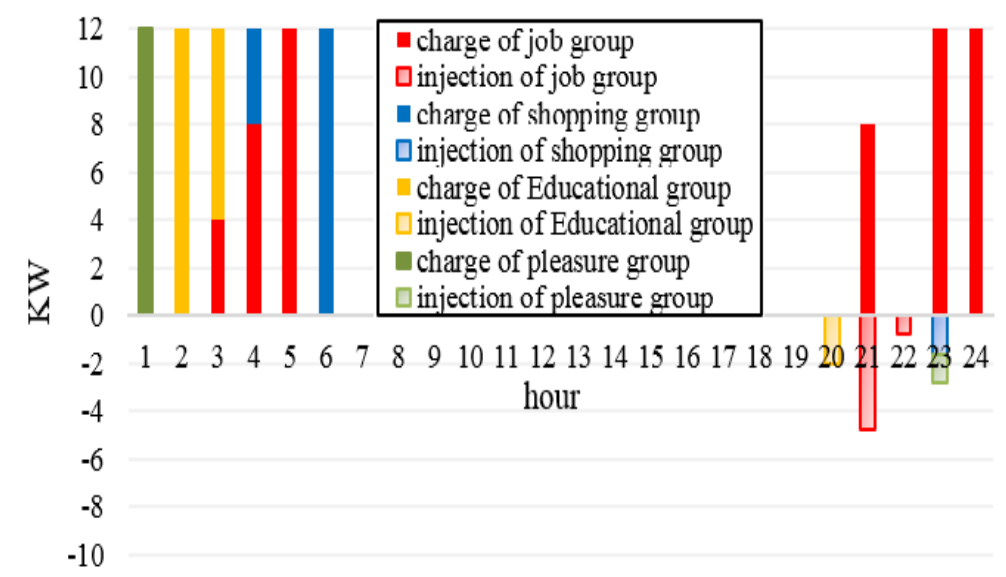

Fig. 6. Optimal planning of vehicles charge/injection (when the remained charge is equal to $10 \%$ of battery capacity)

As we can see in Fig. 6, electric vehicles have proceeded to power injection to the network between 20 to 23 o'clock. According to trip limitations of vehicles, only the vehicles of educational group have proceeded to injection on 20 o'clock. This issue would decrease the load curve on 20 o'clock. In addition, load growth level on 21 and 23 o'clock is restricted by vehicles discharge. The low level of vehicles discharge is due to the low amount of remained energy in battery. Planning of vehicles for delivering their remained power to the network, related to case 5, is depicted in Fig. 7.

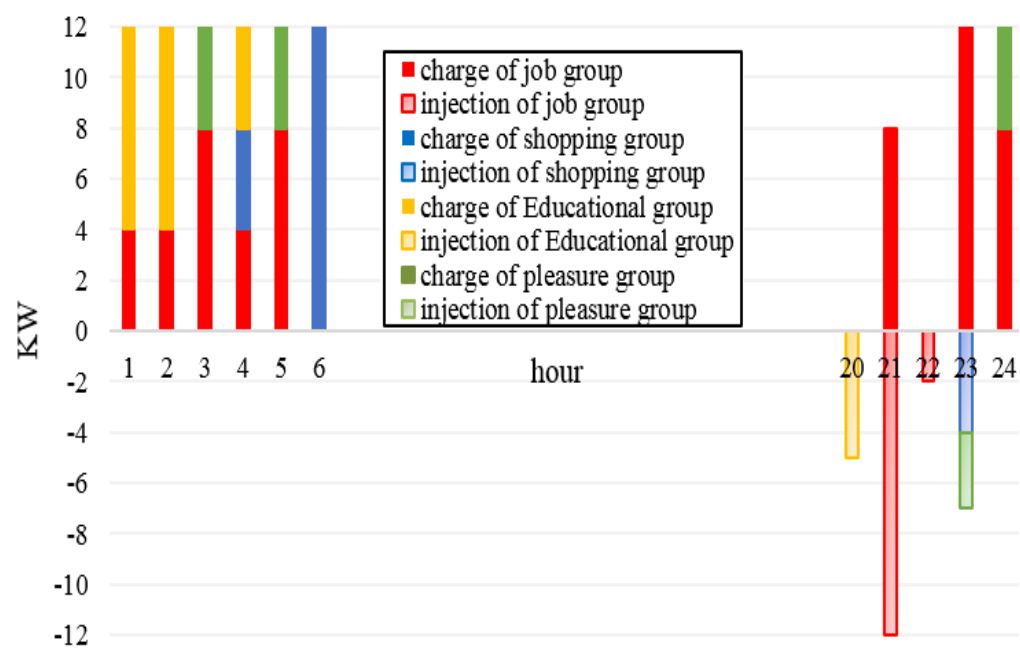

Fig. 7. Optimal planning of vehicles charge/injection (when the remained charge is equal to $25 \%$ of battery capacity)

According to Fig. 7, decrease in consumed load is happened between 20 to 23 o'clock. Considering more remained charge in this case, consumed load in mentioned hours is decreased more compared to Fig. 7. In this case, consumed load growth level due to vehicles charging in 21 and 23 o'clock is controlled and limited well by other vehicles discharge. Regarding that the maximum number of electric vehicles relates to those with "job" trips objective, hence the charging of these group of vehicles on 21 o'clock seems to be normal. Moreover, it is observed that vehicle charge/injection in each clock has not violated the limitation of station. In Fig. 8, the load curve in all states is shown beside each other, in order to specify the effect of optimal charge/injection planning on peak load of network. 


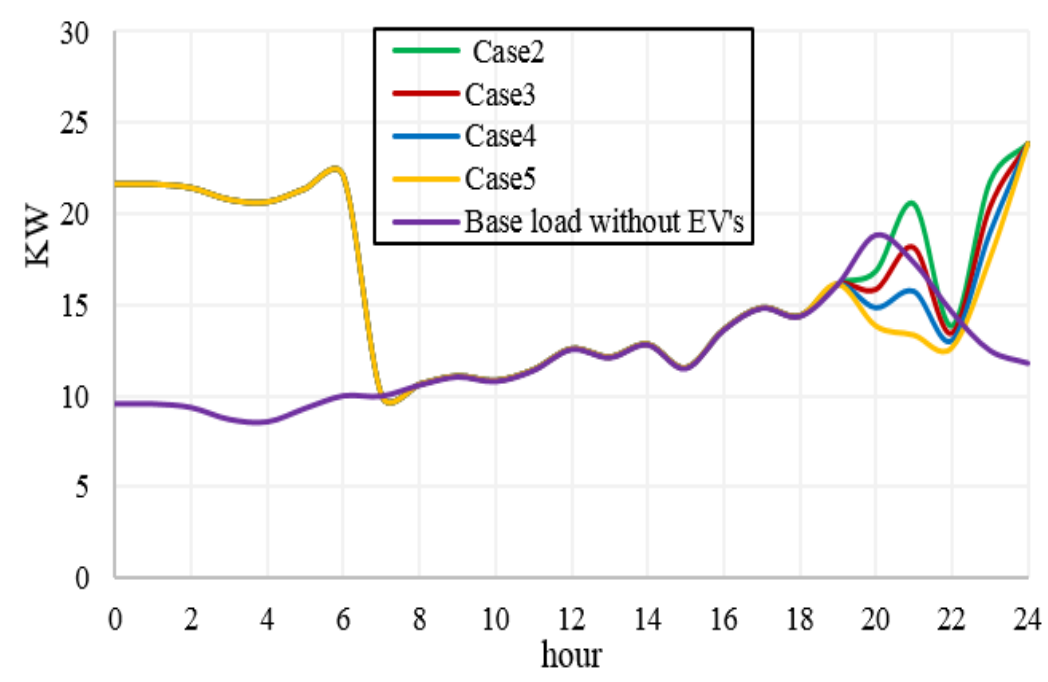

Fig. 8. The load curve in second scenario (optimal planning of vehicles charge/injection)

As it can be seen in Fig. 8, peak shaving is happened in peak load in all cases. Power injection to the network by electric vehicles is the reason for peak shaving. Vehicles owners decide to sell the available energy in battery in times that the consumed load is in its high level and the price of energy buying and selling in network is high. However, the peak load hour is changed from 20 to 24 o'clock with this planning. The impact of electric vehicle presence on the load curve is shown in table (VVIVII).

TABLE VIIIIXX. The Impact of Optimal Planning of Vehicles Charge/Injection on the Load Curve

\begin{tabular}{|c|c|c|c|}
\hline Case & Peak Load & Average Load & Consumed Load \\
\hline 2 & $23.80 \mathrm{Kw}$ & $16.05 \mathrm{Kw}$ & $385.25 \mathrm{Kw}$ \\
\hline 3 & $23.80 \mathrm{Kw}$ & $15.83 \mathrm{Kw}$ & $380.05 \mathrm{Kw}$ \\
\hline 4 & $23.80 \mathrm{Kw}$ & $15.61 \mathrm{Kw}$ & $374.85 \mathrm{Kw}$ \\
\hline 5 & $23.80 \mathrm{Kw}$ & $15.40 \mathrm{Kw}$ & $369.65 \mathrm{Kw}$ \\
\hline Without EV & $18.80 \mathrm{Kw}$ & $12.15 \mathrm{Kw}$ & $291.65 \mathrm{Kw}$ \\
\hline
\end{tabular}

The battery energy of vehicles is in its lowest level after discharge and it must proceed to charge itself fully for next trip. Therefore, peak load level is increased due to full charging of vehicles. The consumed energy of 2, 3,4 and 5 cases is decreased respectively, which is completely expectable. Moreover, it is obvious that observing the technical requirements of charge/injection planning has caused the peak load level not to exceed $23.8 \mathrm{~kW}$.

\section{Comparison of First and Second Scenarios Results}

In this section, acquired results from simulation of first (only the planning of charging) and second (planning of charge/injection) scenarios are compared. Load factor index defined by equation (10) is used for clear evaluation of load curve before and after charge planning of electric vehicles.

$$
\begin{gathered}
L_{a}=\frac{E_{a}}{24} \\
L_{f}=\frac{L_{a}}{L_{P}}
\end{gathered}
$$

In equation (9), $L_{a}$ is the averaged consumed load of system, and $E_{a}$ represents the energy of consumed load curve. $L_{f}$ and $L_{p}$ are load factor index and peak consumed load level respectively. In Fig. 9, load factor of overall consumed curve in both scenarios is drawn for different cases of remained battery energy. 


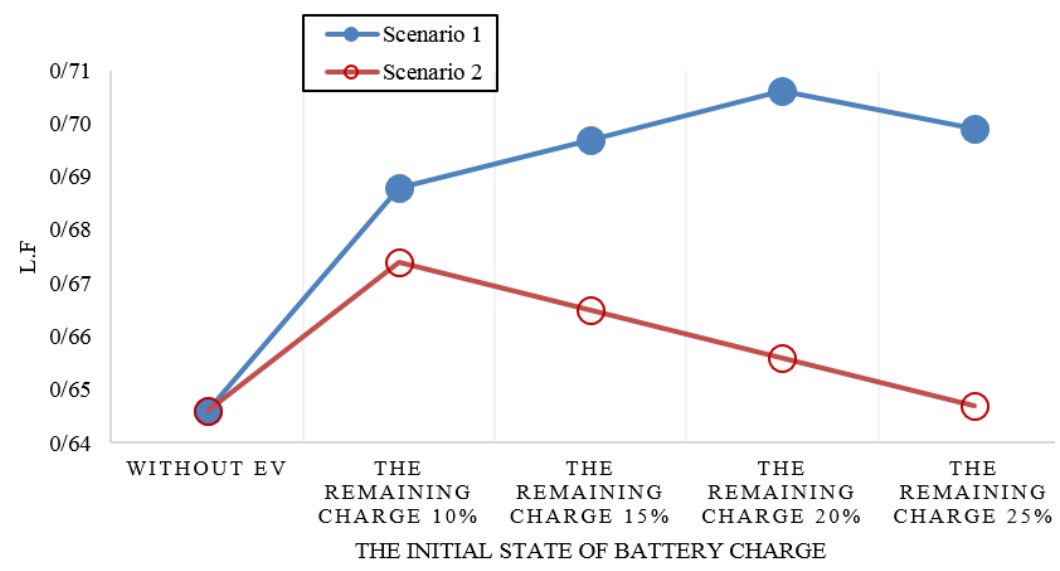

Fig. 9. The load factor index in first and second scenarios for different cases

According to Fig. 9, it can be seen that the planning of load factor level is increased in both scenarios compared to the time which electric vehicles are not considered. In first scenario, load factor is increased often by increasing the remained charge because, the load arise from charging is added to transformer load in low load hours. However in second scenario, load factor has decreasing trend with increasing the remained battery energy. The nonlinearity of load factor was effective in acquiring such results.

In Fig. 10, the cost paid by electric vehicles owners is compared considering the contribution and disaffiliation of vehicles in injection.

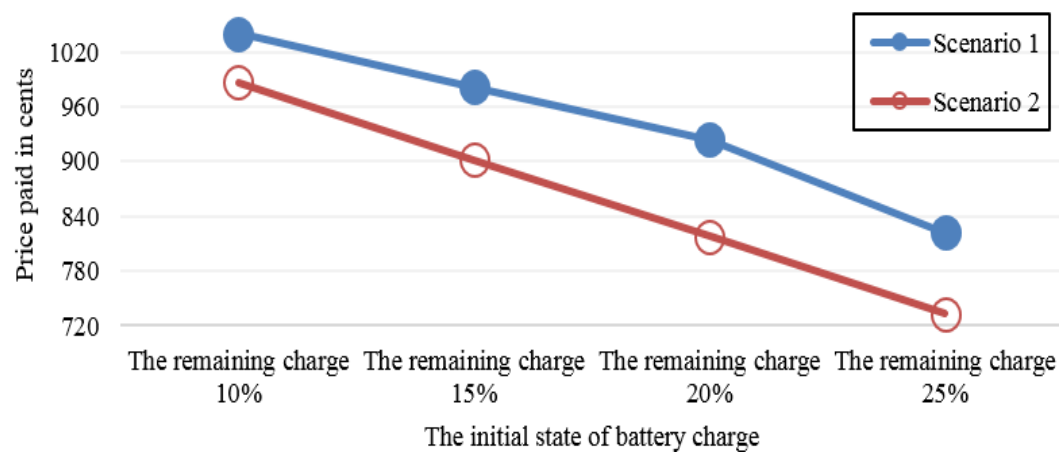

Fig. 10. The cost paid in both scenarios for different cases

It is observed that the total cost paid for charging the vehicles by owners who have contributed in injection of their battery in the network and then have proceeded to charge, is less than the case which owners proceed to charge the vehicle in the network (in fact, the earned income from selling a part of charge is subtracted from vehicles owners costs). Moreover according to the figure, paid cost is more in cases that the remained charge is less, which this issue is expectable. . Due to fast charging rate, owners are able to select the best hours and price in terms of buying the energy from network (and also selling the remained charge), and pay the lowest possible cost. However in this planning, time limitations of trip program and also restrictions of charging station are observed well.

\section{Conclusion}

A new model is presented to optimally plan charge/injection of electric vehicles with different trip types, in this paper. The main considered constraints of the optimization problem are included time scheduling of trips and station charging limitations. The simulations is performed for two scenarios (first scenario: only optimal charging, and second scenario: optimal charge and injection) and a few different cases of remaining charge of battery. Load curve peak shaving and valley filling are two advantages of proposed planning method. In all cases, the second scenario results less cost compared to first scenario, which is due to earn money obtained from the remaining charge selling. Investigation of the load curve, in both scenarios and in all cases, demonstrates that in the proposed planning the technical requirements and constraints of charging station are observed well. The obtained planning for charging/injection based on different electricity price and time schedule of trips lead to customer satisfaction and increasing the benefit of system operator. 


\section{REFERENCES}

[1] Yijia Cao , Shengwei Tang , Canbing Li, Peng Zhang, Yi Tan , Zhikun Zhang and Junxiong Li, “ An Optimized EV Charging Model Considering TOU Price and SOC Curve, ” IEEE Trans. Smart Grid ,vol. 3, no. 1, pp. 388-393, 2012.

[2] A. S.Masoum, S. Deilami, P. S. Moses,M. A. S. Masoum and A. Abu-Siada, "Smart load management of plug-in electric vehicles in distribution and loss minimization considering voltage regulation,” Journal of IET Generation, Transmission\& Distribution, vol. 5, no. 8, pp. 877-888, 2011.

[3] Ali Ashtari, Eric Bibeau, Soheil Shahidinejad and Tom Molinski, "PEV Charging Profile Prediction and Analysis Based on Vehicle Usage Data,” IEEE Tans. Smart Grid, vol. 3, no. 1, pp. 341-350, 2012.

[4] Jason M. Sexauer, Kerry D. McBEE and Kelly A. Bloch, "Applications of probability model to analyze the effects of electric vehicle chargers on distribution transformers,” IEEE Tans. Power Systems, vol. 28, no. 2, pp. 847-854, 2013.

[5] Niklas Rotering and Marija Ilic, "Optimal Charge Control of Plug-In Electric Vehicles in Deregulated Electricity Markets,” IEEE Tans. Power Systems, vol. 26, no. 3, pp. 1021-1029, 2011.

[6] Camila Pereira Caixeta Fernandes, Pablo Faris and Jesus M. Latorre, "Impact of vehicle-to-grid on power system operation costs: The Spanish case study Energy,” Journal of Applied Energy, vol. 96, pp. 194-202, August 2012.

[7] Sekyung Han, Soohee Han and Kaoru Sezaki, "Development of an Optimal Vehicle-to-Grid Aggregator for Frequency Regulation," IEEE Trans. Smart Grid, vol. 1, no. 1, pp. 65-72, 2010.

[8] S. Andersson, A.K. Elofsson, Matthias David Galus and Goran Andersson, "Plug-in hybrid electric vehicles as regulating power providers: Case studies of Sweden and Germany,” Journal of Energy Policy, vol. 28, no. 6, pp. 2751-2762, 2010.

[9] Linni Jian, Xinyu Zhu , Ziyun Shoa, Shuangxia Niu and C.C. Chan "A scenario of vehicle-to -grid implementation and its doublelayer optimal charging strategy for minimizing load variance within regional smart grids ,"Journal of Energy Conversion and Management ,vol. 78, pp. 508-517, February 2014.

[10] Shengnan Sho, Manisa Pipattanasomporn and Saifur Rahman“ Demand Response as a Load Shaping Tool in an Intelligent Grid with Electric Vehicles,” IEEE Trans. Smart Grid, vol. 2, no. 4, pp. 624-631, 2011.

[11] Monica Alonso, Hortensia Amaris, Jean Gardy Germain and Juan Manuel Galan“ Optimal Charging Scheduling of Electric Vehicles in Smart Grids by Heuristic Algorithms, "Journal of Energies, vol. 7, no. 4, pp. 508-517, 2014.

[12] Linni Jian, Honghong Xue, Guoqing Xu , Xinyu Zhu , Dongfang Zhao and Z. Y. Shoa“ Regulated Charging of Plug-in Hybrid Electric Vehicles for Minimizing Load Variance in Household Smart Micro grid ,"IEEE Trans. Industrial Electronics, vol. 60, no. 8, pp. 3218-3226, 2013.

[13] Florian Hausler, Emanuele Crisostomi, Arieh Schlote, Ilja Radusch and Robert Shorten "Stochastic Park-and-Charge Balancing for Fully Electric and Plug-in Hybrid Vehicles,” IEEE Trans. Intelligent Transportation Systems, vol. 15, no. 2, pp. 895-901, 2014.

[14] Pedro Sanchez-Martin, Guillermo Sanchez and German Morales "Direct Load Control Decision Model for Aggregated EV Charging Points,” IEEE Trans. Power Systems, vol. 27, no. 3, pp. 1577-1584, 2012.

[15] Xin Gong and Tao Lin “Optimal Decision-making on Charging of Electric Vehicles,” Indonesian Journal of Electrical Engineering and Computer Science, vol. 12, no. 4, pp. 2431-2438, 2014

[16] Ziming Zhu, Sangarapillai Lambotharan, Woon Hau Chin and Zhong Fan "A stochastic optimization approach to aggregated electric vehicles charging in smart grids," in Proceedings of IEEE Innovation Smart Grid Technologies-Asia(ISGT ASIA) Conference, pp. 5156, 2014.

[17] Alireza Zakariazadeh, Shahram Jadid and Pierluigi Siano "Multi objective scheduling of electric vehicles in smart distribution system,” ELSEVIER Trans. Energy Conversion and Management, vol. 79, pp. 43-53, March 2014.

[18] Francesco Alesiani and Nitin Maslekar “Optimization of Charging Stops for Fleet of Electric Vehicles: A Genetic Approach,” IEEE Trans. Intelligent Transportation Systems, vol. 6, no. 3, pp. 10-21, 2014.

[19] Justin M. Foster and Michael C. Caramanis "Optimal Power Market Participation of Plug-in Electric Vehicles Pooled by Distribution Feeder,” IEEE Trans. Transactions on Power Systems, vol. 28, no. 3, pp. 2065-2076, 2013.

[20] (2016) Transportation of Tehran website. [Online]. Available: http://en.tehran.ir/default.aspx?tabid=103

\section{APPENDIX}

TABLE IV. The Electricity Price (cent/kWh)

\begin{tabular}{|c|c|c|c|c|}
\hline Hour & $\mathbf{1 - 7}$ & $\mathbf{8 - 1 8}$ & $\mathbf{1 9 - 2 2}$ & $\mathbf{2 3 - 2 4}$ \\
\hline The Sales Price to the Customer & 10.5 & 13 & 17 & 11 \\
\hline The Purchase Price from the Customer & 11 & 14 & 18 & 11.5 \\
\hline
\end{tabular}

